\title{
Non-nutritional "paramedical" usage of human milk - knowledge and opinion of breastfeeding mothers in Poland
}

\author{
Karolina Karcz ${ }^{1} \mathbb{D}^{\text {, Julia Makuch}}{ }^{\mathbb{D}}$, Mateusz Walkowiak² ${ }^{\mathbb{D}}$, \\ Igor Olejnik ${ }^{3}$, B , Barbara Krolak-Olejnik ${ }^{1}[D$ \\ ${ }^{1}$ Departament of Neonatology, Wroclaw Medical University, Wroclaw, Poland \\ ${ }^{2}$ Neonatology and Neonate Intensive Care Students Scientific Association, Wroclaw Medical University, Poland \\ ${ }^{3}$ Department of Paediatric Bone Marrow Transplantation, Oncology and Hematology, Wroclaw Medical Uniersity, Poland
}

\begin{abstract}
Objectives: The objective of this study is to understand knowledge, attitudes and practices of non-nutritional breast milk use among lactating women in respect of skin diseases and other frequent ailments.

Material and methods: The study, in the form of a questionnaire, spread on social media, was targeted at breastfeeding women. The questionnaire consisted of questions regarding the knowledge of non-nutritional usage of human milk, its use in practice, subjective opinion on the observed results and inclination towards future use. Chi-square tests and c-Pearson coefficients were used for statistical calculations.

Results: A total of 1187 responses were acted upon. In the study group, 879 women claimed to have knowledge of non-nutritional use of human milk in respect of skin and most common ailments, whilst 688 of them claimed to use at least one usage. The most frequently, breast milk was used for: care of cracked nipples, care of healthy skin, treatment of diaper dermatitis and treatment of neonatal acne. A correlation between duration of breastfeeding $(p<0.05)$ and gestational age $(p<0.05)$ and practical use of non-nutritional human milk was found.

Conclusions: The study showed a great enthusiasm of mothers in respect of using breast milk for non-nutritional purposes, including the treatment of skin diseases and other common ailments. However, given the scant studies determining possible concerns surrounding these methods, there is a requirement for parental education with emphasis on the need for prompt medical examination and pertinent treatment.
\end{abstract}

Key words: breast milk; milk therapy; skin; constipation

Ginekologia Polska 2020; 91, 2: 79-84

\section{INTRODUCTION}

For centuries, usage of home remedies has been a common practice around the world, especially in medium-intensity ailments [1]. Recently, one has been able to observe increasing popularity of alternative treatment among Polish society, primarily of those with use of easily accessible natural remedies. Moreover, self-treatment is often administered on the basis of information found in social media, without any medical consultation [2]. The rise of interest in those methods might result from a general belief in safety, efficacy and lack of side effects associated with them. Patients' practices include the non-nutritional use of human milk, which seems to be confirmed by mothers consulting in the authors' Clinic of Neonatology.

First mentions of therapeutical usage of breast milk were found thousands of years ago, and opinions of its efficacy were passed along to consecutive generations. Authentication of non-dietary use of human milk and scientific argumentation of its use as an alternative to generally approved medical remedies is still sought $[1,3]$. Human milk is optimally adjusted to the needs of infants, both in nutritional components and non-nutritional bioactive compounds, which stimulate normal child development, further immunological maturing and defence against various 
diseases - both infectious and autoimmunological [4, 5]. Studies concerning human milk's mechanics in aiding child development and stimulating the immune system identified various compounds, including cytokines, stem cells, oligosaccharides, growth factors, anti-inflammatory and antibacterial proteins with potential for preparation of new clinical treatments [6]. Currently, in social media and the press, one can find information regarding potential methods of human milk use as a home remedy, both in prophylactic and therapeutic purposes, yet the majority of those methods and their potential advantages are not scientifically proven.

\section{Objectives}

According to the authors' experience, non-nutritional usage of human milk is willingly practiced by breastfeeding mothers, although the scale of these practices has not been studied in Poland to date. Therefore, the objective of this study is to understand lactating women's knowledge, attitudes and practices of non-nutritional breast milk use. The survey results on the use of mothers' milk as a therapy for mucosal infections of various types in Poland has been previously reported in Part 1 [7]. The present work is a reference to practices of breast milk usage in prophylaxis and treatment of skin ailments and other common health conditions.

\section{MATERIAL AND METHODS}

The study was conducted in November/December 2018 with use of an anonymous questionnaire disseminated in electronic form through social media. The survey targeted women with an ongoing lactation period - breastfeeding or feeding with their own pumped milk (the use of a breast pump and a bottle was allowed), regardless of the duration of lactation. The questionnaire consisted of questions regarding the knowledge of non-nutritional use of human milk, its use in practice, subjective opinion on the observed results and inclination for future use. The list of non-nutritional uses of breast milk was compiled from information found on Internet forums, social media and parenting blogs - the responding mothers were well informed that little or no scientific data were currently available regarding the efficacy and dangers of implementation of those usages. The detailed description of study design and methodology was reported in Part 1 [7].

All answers were coded based on the order and date of receipt. The PQStat, version 1.6., and Microsoft Excel for Office 365 were employed to analyse the resulting data. The Chi-square test was used to investigate the statistical correlation between the categorical variables, and the measure of the relationship between nominal variables was determined using c-Pearson coefficient. The statistical significance level was set at $p<0.05$.
Prior to the start of the study, formal permission was obtained from the local ethics committee, the Bioethical Committee at the Medical University in Wroclaw (Nr KB 703/2018, 22 November 2018).

\section{RESULTS}

A total of 1218 women replied to the questionnaire, of which 31 were excluded from the study in view of the unfulfilled basic qualifying criterium - current lactation period. A total of 1187 responses were acted on. In the study group, 890 (74.98\%) women affirmed to having known about non-nutritional usage of breast milk, of those 879 (98.76\%) claimed to have known of those methods in respect of skin maintenance, 47 of those answers included constipation treatment (Tab. 1). The most frequently known of usages: maintenance of damaged nipples ( $n=832$ ), healthy skin maintenance $(n=612)$, atopic dermatitis treatment $(n=387)$ and diaper dermatitis treatment $(n=360)$ (Fig. 1).

Seven hundred fifty-one of all surveyed mothers tried certain methods as a home remedy, of those 688 in skin ailments (Tab. 1). Three hundred forty-seven women used breast milk only in skin care and obstruction treatment, 341 used breast milk in skin care, constipation treatment and in mucous membranes care. The remaining 63 mothers

\begin{tabular}{|c|c|c|}
\hline Demographic data & $\begin{array}{l}\text { Knowledge of } \\
(n=879 ; 98.76 \%)\end{array}$ & $\begin{array}{l}\text { Tried }(n=688 \\
77.3 \%)\end{array}$ \\
\hline \multicolumn{3}{|l|}{ Age in years (Mean $\pm S D$ ) } \\
\hline & $30.17 \pm 3.99$ & $30.16 \pm 4.05$ \\
\hline \multicolumn{3}{|l|}{ Place of residence $(n)$} \\
\hline Countryside & $160(18.2 \%)$ & $127(18.46 \%)$ \\
\hline City $<100,000$ residents & $217(24.69 \%)$ & $168(24.42 \%)$ \\
\hline City $>100,000$ residents & $502(57.11 \%)$ & $393(57.12 \%)$ \\
\hline \multicolumn{3}{|l|}{ Education (n) } \\
\hline Primary education & $1(0.11 \%)$ & 0 \\
\hline Basic vocational education & $9(1.02 \%)$ & $7(1.02 \%)$ \\
\hline General secondary education & $126(14.34 \%)$ & $100(14.53 \%)$ \\
\hline Tertiary education & 743 (84.53\%) & $581(84.45 \%)$ \\
\hline \multicolumn{3}{|l|}{ Parity (n) } \\
\hline 1 & $555(63.14 \%)$ & $437(63.52 \%)$ \\
\hline 2 & $269(30.6 \%)$ & $209(30.38 \%)$ \\
\hline 3 & $52(5.92 \%)$ & $40(5.81 \%)$ \\
\hline$\geq 4$ & $3(0.34 \%)$ & $2(0.29 \%)$ \\
\hline \multicolumn{3}{|c|}{ Duration of lactation in months (Mean \pm SD) } \\
\hline & $10.59 \pm 8.38$ & $10.91 \pm 8.53$ \\
\hline \multicolumn{3}{|c|}{ Gestational age in weeks (Mean \pm SD) } \\
\hline & $39.16 \pm 2.197$ & $39.20 \pm 2.1$ \\
\hline
\end{tabular}


$\square$ Tried $\square$ Konowledge of

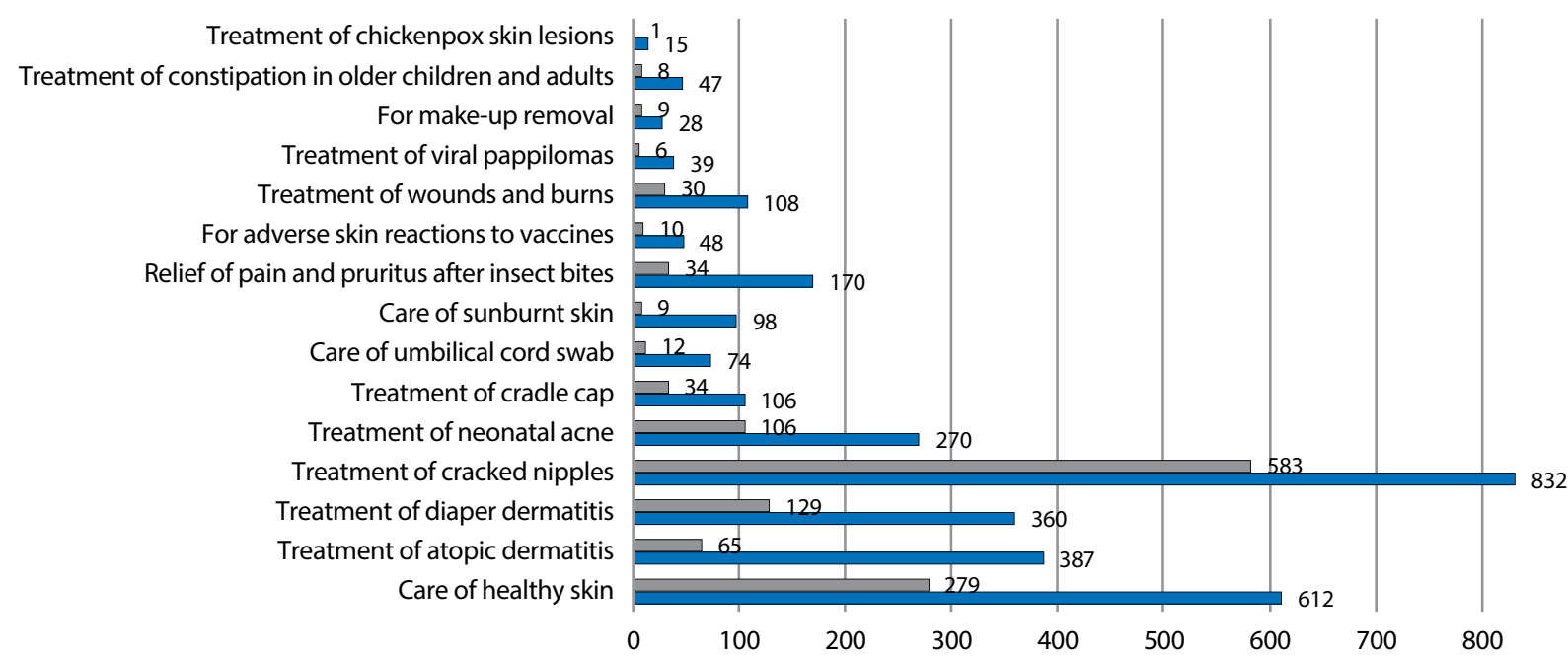

Figure 1. Comparison of the number of mothers who knew of non-nutritional use of human milk in skin care and other frequent ailments („Knowledge of") and those who tried at least one of them („Tried")

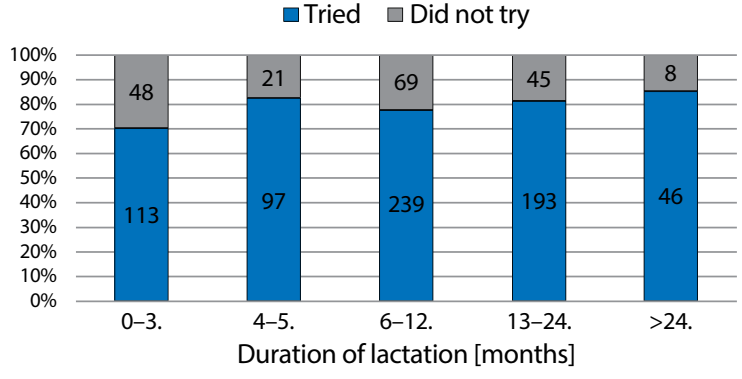

Figure 2. Duration of lactation and attempt of human milk use in prophylaxis and treatment of skin ailments ("Tried" vs "Did not try"). Numbers in graph bars represent a total number of mothers with corresponding percentage in each group

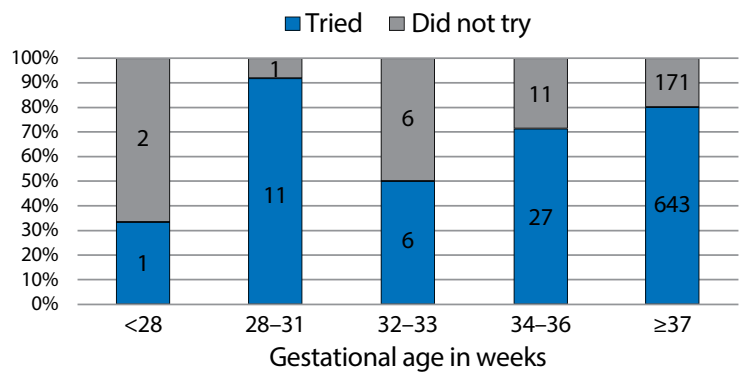

Figure 3. Weeks of gestation and attempt of human milk use in prophylaxis and treatment of skin ailments ("Tried" vs "Did not try"). Numbers in graph bars represent the total number of mothers with corresponding percentage in each group

tried non-nutritional use of human milk in prophylaxis and treatment of mucous membranes ailments. Respondents were asked to evaluate the results and commented upon

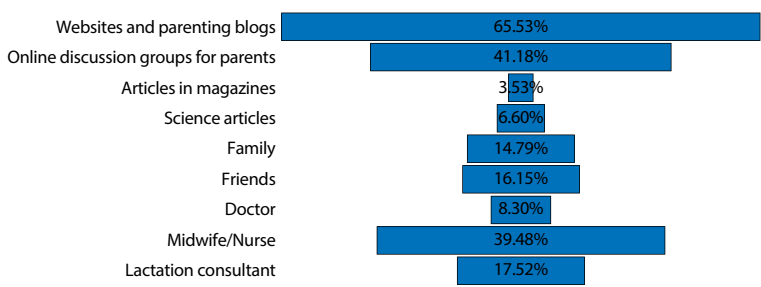

Figure 4. Source of information concerning non-nutritional use of human milk among respondents (multiple choice question)

as follows: 559 positive opinions, 55 negative opinions, and 80 opinions - difficult to assess.

Maintenance of damaged nipples (583), healthy skin care (279), diaper dermatitis (129) treatment of neonatal acne (106) were the most frequently used methods. A correlation between duration of breastfeeding (Chi-square test $=9.97 ; p<0.05 ;$ c-Pearson adjusted coefficient $=0.15$ ) (Fig. 2) and gestational age (Chi-square test $=11.88 ; \mathrm{p}<0.05$; c-Pearson adjusted coefficient $=0.163$ ) (Fig. 3 ) and practical use of non-nutritional human milk in skin and most frequent ailments was found.

The main source of information about non-nutritional human milk usage was constituted by websites and parenting blogs (65.53\%), online discussion groups for parents (41.18\%) and midwife or nurse (39.48\%) (Fig. 4).

\section{DISCUSSION}

In our experience, no attempts to provide statistical data on the use of breast milk as a therapy by lactating mothers in Poland had been made prior to our study. The only identified papers provide reviews of worldwide literature 
with implications to further research in this field [3, 8]. In the following part of the paper, we report on survey results in respect of management of mainly skin conditions with reference to representative studies.

Attempts at using mother's milk as a home medication are a common practice among the mothers surveyed. We noticed a great interest in information regarding possible non-nutritional uses of human milk. Owing to the use of breast milk for damaged or inflamed skin by mothers, special attention should be given to the microbiological purity of human milk. It is important due to the fact of the physiologically immature epidermal barrier in neonates and infants. Studies have proved that colostrum and human milk provide the infant's intestine with mutualistic, commensal and probiotic bacteria. This is an essential discovery, as human milk had been previously considered to be sterile. In fact, a breast-fed infant, with a daily milk supply of about $800 \mathrm{ml}$, consumes from $1 \times 10^{5}$ to $1 \times 10^{7}$ bacteria [9]. The microbiome of human milk consists mainly of genera Staphylococcus and Streptococcus. Among less frequent genera, Bacteroides, Lactobacillus, Propionibacterium, Serratia, Pseudomonas, Corynebacterium and a smaller number of Enterococcus and Bifidobacterium can be found [10]. The transient flora mainly encompasses pathogens like: HIV, HTLV-1, CMV, HBV, HCV, HSV, VZV, EBV, HHV-6, HHV-7, Toxoplasma gondii, Candida spp. and Staphylococcus aureus, Mycobacterium tuberculosis, Escherichia coli, Streptococcus B, Listeria monocytogenes, Coxiella burnetti. Furthermore, incidents of milk-borne infections have been reported [11].

To the authors' knowledge, the impact of human milk microbiome on formation of infantile epidermal flora has not been assessed to date - especially as far as the topical use of breast milk is concerned. In addition to reports of milk-borne infections via the oral route, no specific information on the risk of pathogens transmission in cases of milk applied to damaged skin is available.

The skin connects the organism with the outside environment, which affects the development of the immune system. After birth, the infantile skin microbiota depends on the type of birth and undergoes dynamic changes. Initially, it is almost identical in different parts of the body. The maturation of microbiome and initial stabilization of its structure depend on body region and takes place from the $3^{\text {rd }}$ month of life. The evolution of the dermal bacterial flora can be affected not only by neonatal skin characteristics and structure, but is prone to factors such as: immune system function, antibiotic therapy and environmental exposure, such as a stay in neonatal intensive care unit. The development and maturation of skin microbiome in the neonatal period, especially in premature babies, is crucial to prevent colonization with pathogens and its subsequent progression to generalized infection [12].
Referring to the high level of interest in the non-nutritional properties of breastmilk, several attempts have been made to verify its potential applications.

The commonly known and recommended method of caring for cracked nipples is moisturizing them with women's own milk — which was reflected in the answers of the surveyed mothers. Conclusions derived from studies on this topic remain inconsistent. Regarding the rate of nipple healing and pain relief, in one piece of research, the use of breast milk together with lactation pads resulted in a better effect than using lanolin [13]. Whereas in another, care with hydrogenous lanolin was more effective than female milk application [14]. It was also found, that lanolin and breast milk are similarly effective in the prevention of pain, but they do not prevent the nipples from cracking [15]. Comparison of the effects of using human milk, hydration packs, tea wraps and drying did not confirm the usefulness of any mentioned intervention, especially in expectation of pain relief [16]. The next study proved that interventions with breast milk or hydration packs alter the pain to a lesser extent than drying the nipples, both in prophylaxis and alleviation [17]. Apart from a slight discrepancy with regard to the mentioned studies, moisturizing nipples with breast milk seems to be a quite safe method of nipple care and pain relief.

Among dermatological inflammatory ailments affecting newborns, diaper dermatitis is one of the most common. So far, the scientific research has suggested that human milk is a good and safe therapeutic agent. When locally applied to the irritated area, it alleviated inflammation and limited progression of skin lesions [18]. It was also shown, that therapeutic efficacy of breast milk was comparable to $1 \%$ hydrocortisone ointment with significant improvement in skin condition [19]. However, this study was conducted on a small group of patients. In another piece of research, traditional medicinal products showed a better effect in cases of medium and severe lesions. Better therapeutic effects were achieved with use of protective ointments [20]. Altogether, the promising results seem to support the use of breast milk as an adjunctive remedy for diaper dermatitis.

The efficacy of using human milk, comparable to the effectiveness of $1 \%$ hydrocortisone ointment, was also found in case of skin changes in the course of atopic dermatitis among infants [21,22]. Although there was no difference in the speed of skin condition improvement, patients treated with traditional methods received a significantly lower severity scale score after intervention [21] or the score was comparable [22]. Another study, conducted only on nine patients, did not confirm the beneficial effect of breast milk on atopic eczema lesions. In milk samples used in the study, researchers identified the following bacteria: Staphylococcus aureus, coagulase-negative Staphylococcus and Alpha-Hemolytic Streptococcus. Staphylococcus aureus colonies were also detected after milk application on skin 
with atopic lesions in one child, with their absence within healthy skin areas. However, no signs of infection were found. There were no cases of milk-borne infections [23]. Treatment with fresh human milk seemed easy for mothers - due to its availability and low cost, as compared to pharmaceutical agents [21-23]. The observation was confirmed by the results of our survey.

There are no studies on the possibility of using breastmilk for the treatment of seborrheic dermatitis (including cradle cap) and neonatal acne.

Undoubtedly, mother's milk has a positive impact on building the child's immunity. As mentioned above, numerous bioactive compounds are transferred via the oral route. There are, among others, specific antibodies which stimulate the immature immune system, protect against infections or shorten their duration time $[5,6]$ - which similarly concerns chickenpox. A case of mild and short course of VZV infection in a 41-year-old father and his 9-year-old son after use of frozen breast milk for skin eruptions was reported [24]. Based on the observation, it was hypothesized that breast milk might have shortened the duration of chickenpox. However, it requires verification on the basis of a larger research group. Moreover, it is necessary to assess the risk of superinfection of skin eruptions in relation to using fresh milk.

There is also lack of scientific reports on the usefulness of breast milk in treatment of other viral skin diseases, such as viral papillomas. Despite the proven immunomodulatory and anti-inflammatory properties of human milk [25], there are no studies on the effects of its use in pruritus, insect bites, post-vaccination reactions and care of intact, healthy skin.

As far as the care of the umbilical stump is concerned, it is an important issue in neonatal nursing. Negligence and mistakes in this respect result in impaired healing and development of bacterial infections, which affect $0.2-0.9 \%$ newborns negatively [26]. In order to reduce the infection rate, the World Health Organization recommends washing the umbilical cord stump with clean water and soap, and thorough drying afterwards [27]. The same guidelines were published by the Polish National Supervision in the Field of Neonatology in 2010. They recognize the "dry care" as a standard procedure [26]. Due to the high infant mortality rate resulting from bacterial infections in developing countries, including around 1 million cases of lethal omphalitis annually, the topic of umbilical cord care with use of breast milk as an easily available agent is undertaken [28]. In each of 10 publications found, umbilical stump separation time was reduced, and no side effects were noticed. Moreover the effectiveness of the method was greater than in the case of alcohol [29], distilled water [28] and dry care [29-33]. Furthermore, there was an observed: reduction of bacterial colonization of the umbilical stump [31], reduction of bleeding after separation [30,31], similar frequency of infection as with other factors [30] and lower inci- dence of infection than in case of dry care [33]. Among the surveyed women, 12 used breast milk to care for the umbilical cord-no complications were reported. Altogether, the results of research studies suggest the breast milk might be used as beneficial means of preventing omphalitis.

On the basis of previous studies, it was observed that hard stools and constipation more often occurred in infants fed with milk formula than breast-fed [34]. This difference was partially attributed to human milk oligosaccharides (HMO) - this effect is explained by several mechanisms: 1) increase in microbial mass due to oligosaccharides fermentation may increase the content of water in stools and result in softer consistency; 2) selective fermentation and growth of Lactobacillus and Bifidobacterium spp. and production of short-chain fatty acids may increase the water content in faecal mass, but also stimulate gastrointestinal motor complex activity; 3 ) probably HMOs bind water, thus increase its content in faeces [34]. Scientific research has shown that long exclusive breastfeeding is a protective factor against gastrointestinal dysfunction, including constipation in children at high risk of developing autism spectrum disorder [35]. However, no attempts have been made to verify the suitability of orally administered breast milk in the immediate treatment of abnormal rhythm of bowel movements, especially in different age groups.

This work is a part of the first research in Poland, to the authors' knowledge, on the use of breast milk for non-nutritional purposes by breastfeeding mothers. This paper includes preliminary statistical data on the popularity of using their own milk by mothers during lactation. It provides an overview of patients' knowledge and experience in the application of human milk as a home remedy for skin conditions or other ailments, such as constipation. The survey involved women living in various regions of Poland, of different ages, parity rate and education level. However, the results cannot be generalised on the Polish population, as the study group encompassed breastfeeding internauts.

\section{CONCLUSIONS}

1. Polish mothers show great interest in non-nutritional applications of human milk. Websites (including parenting blogs), social networks and forums for parents are the main source of their knowledge. The information is mainly based on anecdotal evidence.

2. Increasing knowledge of human milk composition and recognizing the multitude of its immunologically active compounds creates the prospect of using breast milk as a cheap and relatively easily available therapeutic agent.

3. So far, the results of research concerning the usefulness of human milk in prevention and treatment of selected skin conditions, especially diaper dermatitis or umbilical cord stump care, prompt the updating of the current 
medical standards, and legitimate breast milk as a supportive remedy.

4. Further research is needed in the field of the usefulness of human milk in treatment of gastrointestinal motility disorders, inflammatory reactions, atopic and seborrheic dermatitis.

5. It is essential to verify the risk of causing human milk microbiome induced infection in case of usage on damaged skin.

\section{Acknowledgements}

We would like to thank Barbara and Robyn Royal for their help in the language correction of the article. We would also like to thank all the respondents for taking part in the study and completing the questionnaire voluntarily.

The publication was prepared under the project financed from the funds granted by the Ministry of Science and Higher Education in the "Regional Initiative of Excellence" programme for the years 2019-2022, project number 016/RID/2018/19, the amount of funding 11998 121.30 PLN.

\section{REFERENCES}

1. Laskaris J. Nursing Mothers in Greek and Roman Medicine. American Journal of Archaeology. 2008; 112(3): 459-464, doi: 10.3764/aja.112.3.459.

2. Komunikat Z Badań Nr 148/2016: Zdrowie Online CBOS, 2016. https:// www.cbos.pl/SPISKOM.POL/2016/K_148_16.PDF (1.03.2019).

3. Piskorska-Jasiulewicz MM, Witkowska-Zimny M. Non-nutritional use of breast milk. Postepy Hig Med Dosw (Online). 2017; 71(0): 860-866, doi: 10.5604/01.3001.0010.5049, indexed in Pubmed: 29039349.

4. Horta BL, Victora CG. World Health Organization. Short-term effects of breastfeeding: a systematic review on the benefits of breastfeeding on diarrhoea and pneumonia mortality. World Health Organization . http:// www.who.int/iris/handle/10665/95585 (1.03.2019).

5. Horta BL, Victora CG. World Health Organization. Long-term effects of breastfeeding: a systematic review. World Health Organization 2013. http://www.who.int/iris/handle/10665/79198 (1.03.2019).

6. Hill DR, Newburg DS. Clinical applications of bioactive milk components. Nutr Rev. 2015; 73(7): 463-476, doi: 10.1093/nutrit/nuv009, indexed in Pubmed: 26011900.

7. Karcz K, Walkowiak M, Makuch J, et al. Non-Nutritional Use of Human Milk Part 1: A Survey of the Use of Breast Milk as a Therapy for Mucosal Infections of Various Types in Poland. Int J Environ Res Public Health. 2019; 16(10), doi: 10.3390/ijerph16101715, indexed in Pubmed: 31100785.

8. Witkowska-Zimny M, Kamińska-El-Hassan E, Wróbel E. Milk Therapy: Unexpected Uses for Human Breast Milk. Nutrients. 2019; 11(5), doi: 10.3390/nu11050944, indexed in Pubmed: 31027386.

9. Fernández L, Langa $\mathrm{S}$, Martín V, et al. The human milk microbiota: origin and potential roles in health and disease. Pharmacol Res. 2013; 69(1): 1-10, doi: 10.1016/j.phrs.2012.09.001, indexed in Pubmed: 22974824.

10. Fitzstevens JL, Smith KC, Hagadorn Jl, et al. Systematic Review of the Human Milk Microbiota. Nutr Clin Pract. 2017; 32(3): 354-364, doi: 10.1177/0884533616670150, indexed in Pubmed: 27679525.

11. Jones CA. Maternal transmission of infectious pathogens in breast milk. J Paediatr Child Health. 2001; 37(6): 576-582, doi: 10.1046/j.1440-1754. 2001.00743.x, indexed in Pubmed: 11903839.

12. Pammi M, O'Brien JL, Ajami NJ, et al. Development of the cutaneous microbiome in the preterm infant: A prospective longitudinal study. PLoS One. 2017; 12(4): e0176669, doi: 10.1371/journal.pone.0176669, indexed in Pubmed: 28448623.

13. Vieira F, Mota DD, Castral TC, et al. Effects of Anhydrous Lanolin versus Breast Milk Combined with a Breast Shell for the Treatment of Nipple Trauma and Pain During Breastfeeding: A Randomized Clinical Trial. J Midwifery Womens Health. 2017; 62(5): 572-579, doi: 10.1111/jmwh.12644, indexed in Pubmed: 28887855.

14. Abou-Dakn M, Fluhr JW, Gensch M, et al. Positive effect of HPA lanolin versus expressed breastmilk on painful and damaged nipples during lacta- tion. Skin Pharmacol Physiol. 2011; 24(1):27-35, doi: 10.1159/000318228, indexed in Pubmed: 20720454.

15. Akkuzu G, Taskin L. Impacts of breast-care techniques on prevention of possible postpartum nipple problems. Prof Care Mother Child. 2000; 10(2): 38-41, indexed in Pubmed: 11040764.

16. Hewat RJ, Ellis DJ. A comparison of the effectiveness of two methods of nipple care. Birth. 1987; 14(1): 41-45, doi: 10.1111/j.1523-536x.1987. tb01447.x, indexed in Pubmed: 3646890.

17. Buchko BL, Pugh LC, Bishop BA, et al. Comfort measures in breastfeeding, primiparous women. J Obstet Gynecol Neonatal Nurs. 1994; 23(1): 46-52, doi: 10.1111/j.1552-6909.1994.tb01849.x, indexed in Pubmed: 8176527.

18. Seifi $B$, Jalali S, Heidari M. Assessment Effect of Breast Milk on Diaper Dermatitis. Dermatol Reports. 2017; 9(1): 7044, doi: 10.4081/dr.2017.7044, indexed in Pubmed: 28626535.

19. Farahani LA, Ghobadzadeh M, Yousefi P. Comparison of the effect of human milk and topical hydrocortisone $1 \%$ on diaper dermatitis. Pediatr Dermatol. 2013; 30(6): 725-729, doi: 10.1111/pde.12118, indexed in Pubmed: 23600719.

20. Gozen D, Caglar S, Bayraktar S, et al. Diaper dermatitis care of newborns human breast milk or barrier cream. J Clin Nurs. 2014; 23(3-4): 515-523, doi: 10.1111/jocn.12047, indexed in Pubmed: 23506257.

21. Kasrae H, Amiri Farahani L, Yousefi P. Efficacy of topical application of human breast milk on atopic eczema healing among infants: a randomized clinical trial. Int J Dermatol. 2015; 54(8): 966-971, doi: 10.1111/ijd.12764, indexed in Pubmed: 25640116.

22. Tan ETR, Tianco EAV. King- Ismael D, Dabay-Tan D. Comparison of the Efficacy of Topical Human Breast Milk versus Hydrocortisone 1\% Lotion in the ical Improvement of Atopic Eczema in Infants: A Non-inferiority Trial. J Clin Investigat Dermatol. 2018; 6: 5.

23. Berents TL, Rønnevig J, Søyland E, et al. Topical treatment with fresh human milk versus emollient on atopic eczema spots in young children: a small, randomized, split body, controlled, blinded pilot study. BMC Dermatol. 2015; 15: 7, doi: 10.1186/s12895-015-0027-9, indexed in Pubmed: 25935520.

24. Verd S, López E. Management of chickenpox with frozen mother's milk. J Altern Complement Med. 2012; 18(8): 808-810, doi: 10.1089/acm.2011.0472, indexed in Pubmed: 22845343.

25. Arnardottir H, Orr SK, Dalli J, et al. Human milk proresolving mediators stimulate resolution of acute inflammation. Mucosal Immunol. 2016; 9(3): 757-766, doi: 10.1038/mi.2015.99, indexed in Pubmed: 26462421.

26. Kamińska E. Pielęgnacja kikuta pępowiny. Wytyczne Nadzoru Krajowego w dziedzinie neonatologii. Medycyna Praktyczna Pediatria. 2010; 2: 60.

27. World Health Organization. Care of the Umbilical Cord: A Review of evidence (WHO/RHT/MSM/98.4) 1999 . http://euroband.com/Umbicut/article1.htm (1.03.2019).

28. Patel E, Tiwari A. Effect of Topical Application of Breastmilk on Separation Time of Umbilical Cord among Newborn-A Literature Review. International Journal of Nursing Education. 2018; 10(2): 38, doi: 10.5958/09749357.2018.00037.5.

29. Ahmadpour-Kacho M, Zahedpasha Y, Hajian K, et al. The effect of topical application of human milk, ethyl alcohol $96 \%$, and silver sulfadiazine on umbilical cord separation time in newborn infants. Arch Iran Med. 2006; 9(1): 33-38, indexed in Pubmed: 16649375.

30. El Ha, El Fa, Azzam H. Effect of Two Different Cord Care Regimens on Umbilical Cord Stump Separation Time among Neonates at Cairo University Hospitals. J Am Sci. 2011; 7: 920-926.

31. Allam NA. The Effect of Topical Application of Mother Milk on Separation of Umbilical Cord for Newborn Babies. American Journal of Nursing Science. 2015 ; 4(5): 288, doi: 10.11648/j.ajns.20150405.16.

32. Hartono A, Purwanto N. Comparison Effectiveness Breast Milk and Dry Sterile Gauze to Treatment Umbilical Cord. Open Journal of Nursing. 2016; 06(02): 94-99, doi: 10.4236/ojn.2016.62010.

33. Subiastutik E. Topical Breastmilk Fasten the Process of Umbilical Cord Separation and Prevent Infection on Babies. IOSR Journal of Nursing and Health Science. 2017; 06(01): 45-50, doi: 10.9790/1959-0601044550.

34. Scholtens PA, Goossens DAM, Staiano A. Stool characteristics of infants receiving short-chain galacto-oligosaccharides and long-chain fructo-oligosaccharides: a review. World J Gastroenterol. 2014; 20(37): 13446-13452, doi: 10.3748/wjg.v20.i37.13446, indexed in Pubmed: 25309075

35. Penn AH, Carver LJ, Herbert CA, et al. Breast Milk Protects Against Gastrointestinal Symptoms in Infants at High Risk for Autism During Early Development. J Pediatr Gastroenterol Nutr. 2016; 62(2): 317-327, doi: 10.1097/MPG.0000000000000907, indexed in Pubmed: 26230900. 